\title{
Experimental study and empirical model development for self-leveling behavior of debris bed using gas-injection
}

\author{
Songbai CHENG*, Hirotaka TAGAMI*, Hidemasa YAMANO*, Tohru SUZUKI*, Yoshiharu TOBITA*, \\ Yuya NAKAMURA**, Syohei TAKETA**, Sinpei NISHI**, Bin ZHANG**, Tatsuya MATSUMOTO** \\ and Koji MORITA** \\ * Advanced Fast Reactor Cycle System Research and Development Center, Japan Atomic Energy Agency \\ 4002 Narita, Oarai-shi, Ibaraki 311-1393, Japan \\ E-mail: cheng.songbai@jaea.go.jp \\ ** Department of Applied Quantum Physics and Nuclear Engineering, Kyushu University \\ 744 Moto-oka, Nishi-ku, Fukuoka 819-0395, Japan
}

\section{Received 11 November 2013}

\begin{abstract}
Studies on the self-leveling behavior of debris bed are crucial in the assessment of core disruptive accident (CDA) that could occur in sodium-cooled fast reactors (SFR). To clarify the mechanisms underlying this behavior, several series of experiments were elaborately designed and conducted within a variety of conditions in recent years, under the close collaboration between Japan Atomic Energy Agency (JAEA) and Kyushu University (Japan). The current contribution, including knowledge from both experimental analyses and empirical model development, is focused on a recently developed comparatively larger-scale experimental facility using gas-injection to simulate the coolant boiling. Compared to the previous investigations, this facility can achieve a much wider range of gas velocities (presently up to a flow rate of around $300 \mathrm{~L} / \mathrm{min}$ ). Based on the experimental observation and quantitative data obtained, influence of various experimental parameters, including gas flow rate $(\sim 300 \mathrm{~L} / \mathrm{min})$, water depth $(180 \mathrm{~mm}$ and $400 \mathrm{~mm})$, bed volume $(3 \sim 7 \mathrm{~L})$, particle size $(1 \sim 6 \mathrm{~mm})$, particle density (beads of alumina, zirconia and stainless steel) along with particle shape (spherical and non-spherical) on the leveling is checked and compared. As for the empirical model development, aside from a base model which is restricted to predictions of spherical particles, the status of potential considerations on how to cover more realistic conditions (esp. debris beds formed with non-spherical particles), is also presented and discussed. This work, which gives a large palette of favorable data for a better understanding and an improved estimation of CDAs in SFRs, is expected to benefit future analyses and verifications of computer models developed in advanced fast reactor safety analysis codes.
\end{abstract}

Key words : Sodium-cooled fast reactor, Core disruptive accident, Debris bed, Self-leveling, Gas injection, Experimental analyses, Empirical model

\section{Introduction}

During a postulated core disruptive accident (CDA) in a sodium-cooled fast reactor (SFR), possibly as a consequence of rapid quenching and fragmentation of core materials, a multiphase flow system can form that could be composed of a mixture of liquid sodium, molten fuel, molten structure, refrozen fuel, solid fuel pellets, fission gas, fuel vapor, and other materials (Tentner, et al., 2010). Deposition of this system will lead to the formation of debris beds over the core-support structure and/or in the lower inlet plenum of the reactor vessel (as depicted in Fig. 1) (Zhang, et al., 2011). Typically, the debris bed, with particle size widely distributed (possibly ranging from several tens of microns to a scale of millimeters) (Magallon, et al., 1992), will form roughly conically-shaped mounds. However, coolant boiling caused by decay heat, might lead ultimately to leveling of the debris bed (Zhang, et al., 2010, 2011). This mechanism, as illustrated in Fig. 2, defines the term 'debris-bed self-leveling'.

To prevent the penetration of the reactor vessel by molten fuel and distribute molten fuel or core debris formed in a CDA into non-critical configurations, in-vessel retention devices are used in some SFR designs (Waltar and Reynolds, 
1981). A multi-layered debris tray installed in the bottom region of the vessel is one of such devices (Nakai, et al., 2009, 2010). During a hypothetical CDA, after being quenched and fragmented into fuel debris in the lower plenum region, discharged molten fuel is expected to accumulate on the different layers of the debris tray (Nakai, et al., 2009, 2010). To stably remove the decay heat generated from debris bed on the tray, the size, retention capability, and allocation of the tray should be carefully designed. Self-leveling is an important inducing factor to trigger molten fuel to transfer among the trays. Thus, the study on this behavior is of essential importance to the design of the tray. In addition, self-leveling behavior will greatly affect the heat removal capability of debris beds (Zhang, et al., 2010, 2011).

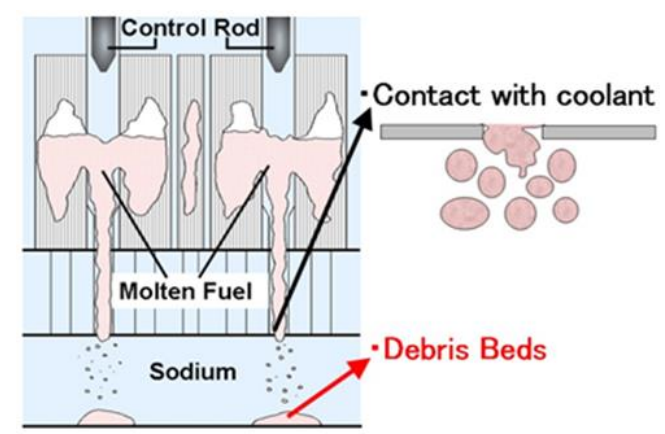

Fig. 1 Schematic illustration of debris bed formation.

Unfortunately, over the past decades very little work related to self-leveling has been performed. Most of the studies generally assume that the upper surface of debris bed is level. Noting the importance of self-leveling in the heat removal capability, Hesson et al. (1971) and Gabor (1974) began some pioneering experimental studies on this subject. In separate experiments, they validated the existence of self-leveling behavior respectively by introducing a bubbling airflow through a particle bed and by volume-heating of a particle bed composed of $\mathrm{UO}_{2}$-salt water. Following these studies, Alvare and Amblard (1982) used copper-water beds to further conclude that boiling even with low power promoted the leveling.
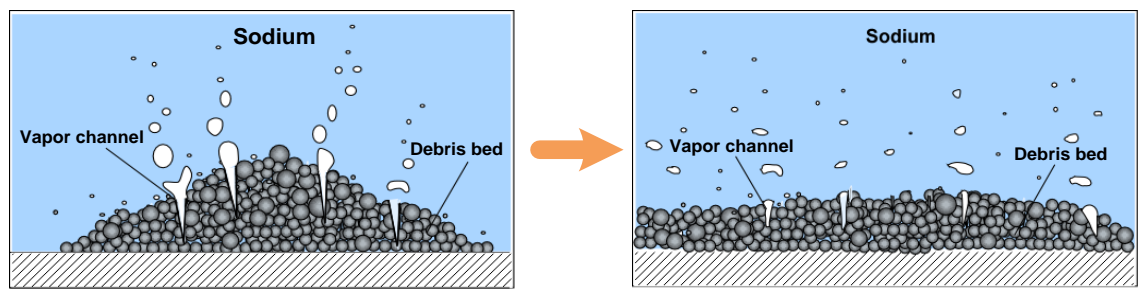

Fig. 2 Self-leveling behavior.

To clarify the mechanisms underlying this behavior, in recent years several series of experiments were elaborately designed and conducted under the collaboration between Japan Atomic Energy Agency (JAEA) and Kyushu University (Japan). Overall, as illustrated in Fig. 3, those experiments can be generally divided into two categories, namely the microscopic flow regime investigations and the macroscopic leveling experiments. Although in real reactor conditions, coolant is heated to boiling point by decay heat, the depressurization boiling instead of more conventional methods was initially used to simulate an axially increasing void distribution in particle beds (Zhang, et al., 2010, 2011). Then, to validate the use of depressurization method, a series of conventional bottom-heated scenarios was conducted (Zhang, et al., 2011). From these experiments, the overall characteristics of leveling, namely the role of experimental parameters (such as particle size, particle density and equivalent boiling intensity) on its onset and development, was recognized (Zhang, et al., 2011). However, noticing that in those experiments the self-leveling behavior is still a black box, to obtain more direct visual evidence (esp. bubble-particle interaction) supporting the overall understandings, therefore, the microscopic flow regime investigations (Cheng, et al., 2010a, 2011a, 2013a), which consist of several series of well-organized tests performed at various bubbling conditions (as shown in Fig. 3), were specifically performed to ascertain the flow characteristics within particle beds. It has been confirmed that by combining the knowledge from flow-regime investigations the observed overall leveling characteristics can be understood more effectively (Cheng, et al., 2013a). 
Since compared to boiling method, a gas phase can be adjusted and controlled more easily using the gas-injection method. Therefore, extensive experimental runs become more viable completion which supports empirical model development and code verifications. For this reason, two series of leveling experiments, namely the quasi-2D small-scale one and a large-scale one (see Fig. 3), were performed. The quasi-2D small-scale one is performed with an aim to check the validity of gas-injection method (Cheng, et al., 2010b, 2011b), while the large-scale one is conducted with the purpose of reducing wall effect as well as achieving experimentation at much larger range of gas velocities possibly needed for the extrapolations of experimental findings (Cheng, et al., 2012). In the previous publication regarding the large-scale apparatus using gas-injection (Cheng, et al., 2012), our attention was primarily focused on verifying the rationale of experimental design (e.g. experimental method for eliminating the disturbance of accumulated liquid in bottom inlet pipelines), although some fundamental experimental parameters (such as gas flow rate, particle size and density) were checked at comparatively higher gas velocities (Cheng, et al., 2012). In this paper, owing to the latest data available, including experimental runs at lower range of gas velocities $(<50 \mathrm{~L} / \mathrm{min})$ needed for empirical model development and potential comparisons with previous investigations (Cheng, et al., 2013b), a variety of experimental parameters are discussed. The analysis of particle shape is of special importance for understanding the actual leveling behavior under reactor conditions. In addition, motivated to further clarify the characteristics of the newly-observed pool convection (Cheng, et al., 2012), the impact of bed volume on the leveling is examined as well.

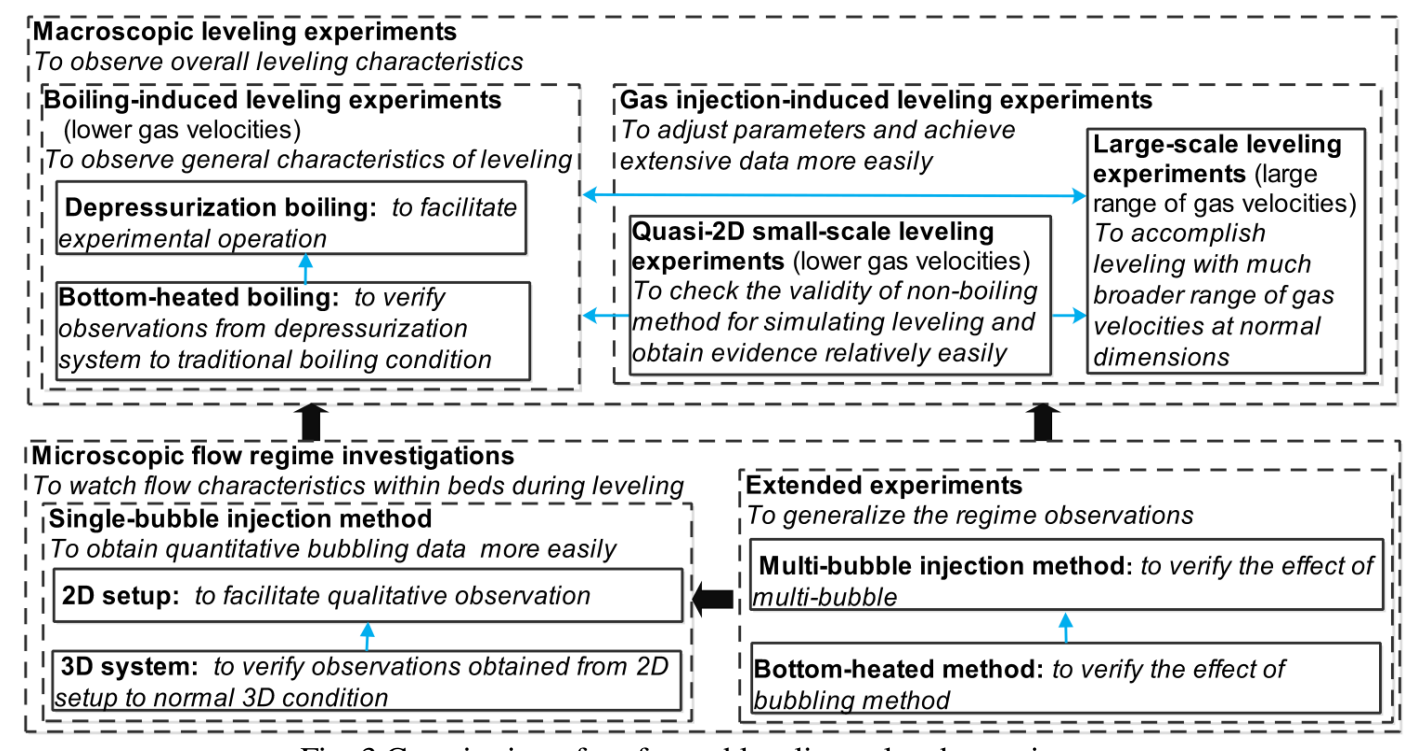

Fig. 3 Constitution of performed leveling-related experiments.

On the other hand, aside from experimental investigations, modeling studies and numerical simulations are also progressing. For instance, owing to the knowledge from the microscopic flow-regime investigations that the self-leveling behavior might be dominated by the solid phase (Cheng, et al., 2010a, 2011a, 2013a, 2014), currently several computer models treating the particle-particle and particle-bubble interactions are being developed and incorporating into SIMMER-III (Guo, et al., 2012a,b; Zhang, et al., 2012), an advanced fast reactor safety analysis code (Tobita, et al., 2006). However, due to the extremely complex and uncertain nature of the three-phase flow involved in the leveling phenomenon (Cheng, et al., 2011b; Zhang, et al., 2010), empirical approach is still regarded as an attractive and indispensable option at present stage because of its distinct advantage in calculation efficiency. On one hand, with an effective empirical model, experimental database can be expanded (interpolated or extrapolated) with much lower cost. On the other hand, the derivation and analyses of empirical approach may provide useful knowledge for computer model improvement and verifications. Focusing on these aspects, originally, based on experimental data from the boiling-induced leveling experiments, an onset criterion was proposed (Zhang, et al., 2010). However, it was later found that too many assumptions, especially the one that the self-leveling of the whole particle bed is represented by the movement of the topmost single particle, might be not always convincible since it ignores many influences inside particle beds (Cheng, et al., 2011b). For this reason, by applying dimensional analysis technique, a new empirical onset model, which was later extended for estimation of the transient behavior, was proposed based on the experimental data from the quasi-2D leveling test (Cheng, et al., 2010b, 2011b). Motivated by the potential of extending this approach to 
actual reactor conditions, recently several validation projects have been initiated with an aim to check its potential wide applicability. The validations involve a great amount of experimental data within various conditions, including some difference in bubbling mode (boiling or gas-injection), bed geometry and dimensions as well as range of experimental parameters (Cheng, et al., 2011b, 2013b, 2014). To provide a more comprehensive knowledge, the status of developing empirical model over the large-scale gas-injection leveling setup is also included in this paper. Specifically, its predictability is examined using several new runs that have not been utilized as a base for modeling derivation. In addition, potential considerations on how to extend this model (hereafter referred to as "base model") to cover more realistic bed conditions (esp. debris beds formed with non-spherical particles) are discussed as well.

\section{Nomenclature}

$\begin{array}{ll}A_{0} & \text { Initial bed angle [degree] } \\ d_{\mathrm{p}} & \text { Particle diameter [mm] or [m] } \\ d_{\mathrm{v}} & \text { Volume-equivalent diameter of non-spherical particle [mm] or [m] } \\ H_{\mathrm{w}} & \text { Water depth [mm] } \\ K_{1}, K_{2} & \text { Correction functions representing additional shape-induced particle-particle interaction [-] } \\ K_{\mathrm{T}} & \text { A correction factor for estimation of } V_{\mathrm{TN}}[-] \\ n & \text { A characteristic exponent defined to express the average leveling rate [-] } \\ \Delta P / H_{\mathrm{pb}} & \text { Pressure drop per unit bed height [Pa/m] } \\ Q_{\mathrm{g}} & \text { Gas flow rate [L/min] or [ml/min] } \\ R(t) & \text { Ratio of inclination angle at time } t \text { to the initial angle }(0 \mathrm{~s})[-] \\ R e_{\mathrm{T}} & \text { Particle Reynolds number based on } d_{\mathrm{v}} \text { at its terminal velocity[-] } \\ t & \text { Time [s] } \\ t_{0} & \text { A given or specific time [s] } \\ U_{\mathrm{g}}\left(\text { or } U_{\mathrm{f}}\right) & \text { Superficial velocity of gas (or fluid)[m/s] } \\ U_{\mathrm{gc}} & \text { Critical gas velocity [m/s] } \\ V_{\mathrm{pb}} & \text { Bed volume [L] } \\ V_{\mathrm{T}}, V_{\mathrm{TN}} & \text { Terminal velocity of a single sphere and non-sphere in stagnant liquid, respectively [m/s] } \\ V_{\mathrm{TS}} & \text { Terminal velocity of a sphere having the same volume }\left(d_{\mathrm{v}}\right)[\mathrm{m} / \mathrm{s}]\end{array}$

\section{Greek Letters}

$\begin{array}{ll}\varepsilon & \text { Voidage [-] } \\ \varepsilon_{\mathrm{s}} & \text { Solid holdup [\%] } \\ \varphi & \text { Particle sphericity [-] } \\ \rho_{\mathrm{l}}\left(\text { or } \rho_{\mathrm{f}}\right) & \text { Liquid (or fluid) density }\left[\mathrm{kg} / \mathrm{m}^{3}\right] \\ \rho_{\mathrm{p}} & \text { Particle density }\left[\mathrm{kg} / \mathrm{m}^{3}\right] \\ \mu_{1}\left(\text { or } \mu_{\mathrm{f}}\right) & \text { Liquid (or fluid) viscosity }[\mathrm{Pa} \cdot \mathrm{s}] \\ \sigma_{1} & \text { Liquid surface tension }[\mathrm{N} / \mathrm{m}]\end{array}$

\section{Experimental conditions}

Figure 4 shows the schematic diagram of the large-scale gas-injection experimental setup used in this work. To permit visual observation and video-recording, a transparent cylindrical tank, with the effective dimensions of $310 \mathrm{~mm}$ in inner diameter and $1000 \mathrm{~mm}$ in height, was utilized. Purified water and nitrogen gas were employed to simulate the coolant and vapor (generated by coolant boiling), respectively. Water was poured into the tank from the top of the tank and water-depth was adjusted to target values $(400 \mathrm{~mm}$ or $180 \mathrm{~mm}$ ) before commencing each experimental run. Nitrogen gas was released into the tank from the bottom. Here, as aforementioned, gas-percolation was chosen instead of more conventional boiling ways (such as bottom-heated or volume-heated) because in this way the gas phase could be adjusted and controlled more easily. To ensure a comparatively uniform percolation of nitrogen gas, over the bottom of the test tank porous media were utilized as gas distributor. By regulating the gas delivery pressure, it is validated that this system, with five nitrogen gas vessels equipped, a driving flow rate up to $10000 \mathrm{~L} / \mathrm{min}$ (equivalent to boiling 
intensities of several tens of $\mathrm{W} / \mathrm{cm}^{3}$ potentially expectable at reactor accident conditions) is theoretically feasible (Cheng, et al., 2013a).

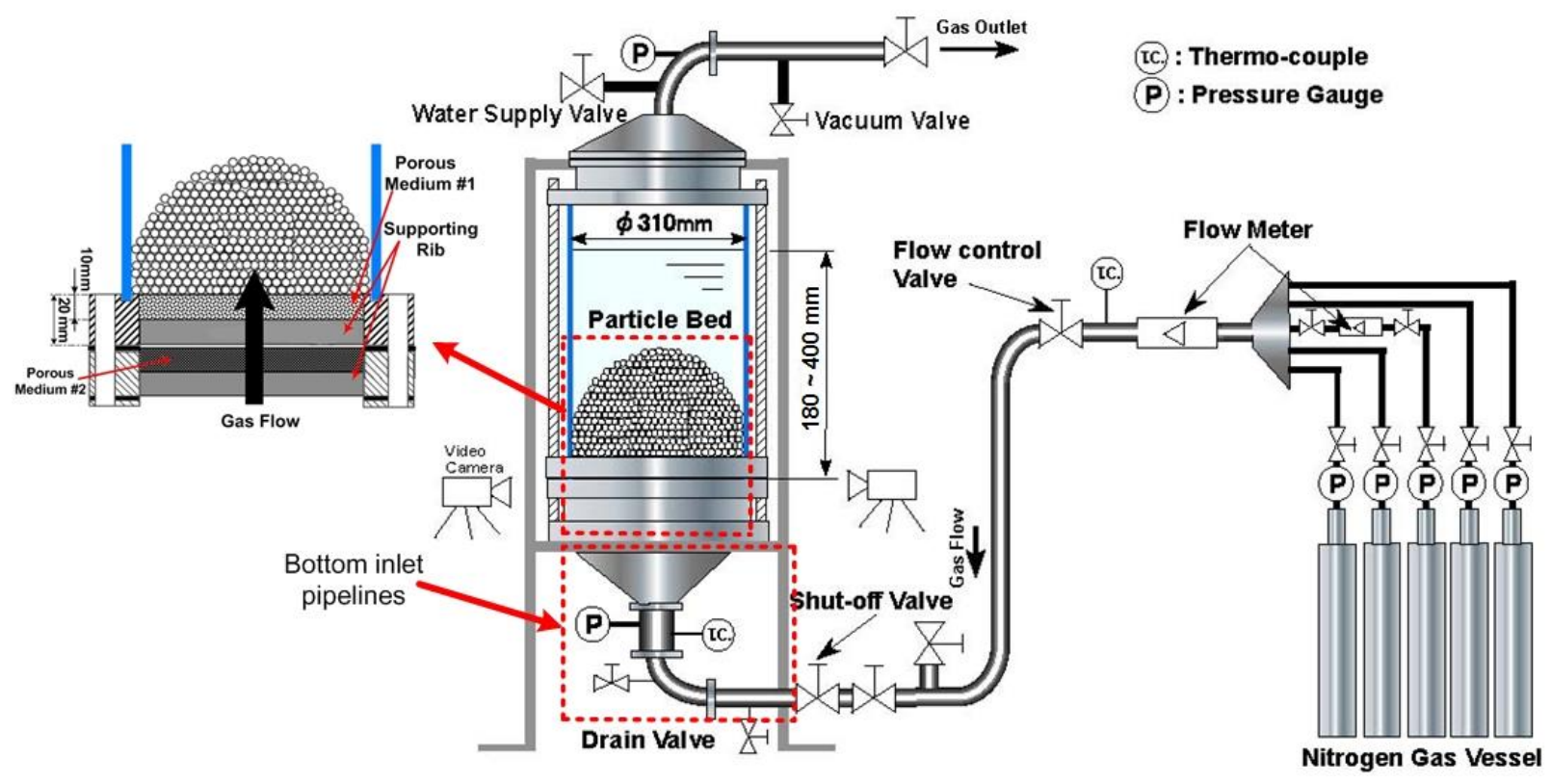

Fig. 4 Schematic view of experimental setup.

In all experimental runs, a certain volume of solid particles was deposited into the tank to form a conically-shaped particle bed that simulates the debris beds generated during CDAs. Before importing nitrogen gas, the initial bed-shape has been well checked to ensure that the initial bed angle (defined later in Fig. 6) varies within a comparatively narrower range (e.g. around 20 degree). Currently, particle beds were formed with three types of particles (namely alumina, zirconia and stainless steel) of varying sizes and shapes. Table 1 lists the physical properties of these particles, while Fig. 5 further shows a photograph comparing the two alumina particles of different shapes. Since in real reactor conditions, debris beds are formed with particle size more widely distributed, here $1 \mathrm{~mm}$ alumina particle is newly utilized (Cheng, et al., 2012).

Table 1 Physical properties of particles used.

\begin{tabular}{|c|c|c|c|c|c|}
\hline Material & Shape & $d_{\mathrm{p}}[\mathrm{mm}]$ & $\rho_{\mathrm{p}}\left[\mathrm{kg} / \mathrm{m}^{3}\right]$ & $\varepsilon_{\mathrm{s}}[\%]$ & $V_{\mathrm{T}}{ }^{\mathrm{a}}[\mathrm{m} / \mathrm{s}]$ \\
\hline \multirow{5}{*}{ Alumina } & \multirow{4}{*}{ sphere } & 1.0 & \multirow{5}{*}{3600} & 58.4 & 0.22 \\
\hline & & 2.0 & & 61.2 & 0.37 \\
\hline & & 4.0 & & 62.7 & 0.59 \\
\hline & & 6.0 & & 59.1 & 0.73 \\
\hline & non-sphere & $0.85 \sim 1.18$ & & 53.0 & $0.28^{b}$ \\
\hline \multirow{3}{*}{ Zirconia } & \multirow{3}{*}{ sphere } & 2.0 & \multirow{3}{*}{6000} & 62.1 & 0.53 \\
\hline & & 4.0 & & 61.5 & 0.83 \\
\hline & & 6.0 & & 59.3 & 1.01 \\
\hline \multirow{2}{*}{ Stainless steel } & sphere & 2.0 & \multirow{2}{*}{7800} & 61.8 & 0.64 \\
\hline & non-sphere & $2.0 \sim 2.4$ & & 62.4 & $0.69^{b}$ \\
\hline
\end{tabular}

${ }^{a}$ Estimated in water using Stokes's law for small particles, and Heywood tables for larger particles (Holdich, 2002).

${ }^{\mathrm{b}}$ Evaluated using the volume-equivalent diameter $d_{\mathrm{v}}$.

It is observed that due to the gravity as well as voids existing within particle beds and porous media, liquids poured into the test tank could immediately penetrate and fill up the bottom inlet pipelines (see Fig. 4), even prior to the start-up of each experimental run. These accumulated liquids, with a sudden triggering from the gas flow injected afterwards, will flood upwards and collapse the particle mounds within split seconds. To alleviate the disturbance from 
accumulated liquids, two experimental approaches, namely the so-called gas pre-charge and pressure-adjustment methods, have been tested. The gas pre-charge method attempts to reduce the liquid impact by employing a lento pre-charging process, while for the pressure-adjustment approach, it aims on eliminating all the accumulated liquids out of the bottom inlet pipelines by creating and keeping a comparatively lower pressure within the test tank. In our earlier publications, through detailed quantitative analyses and comparisons, it has been confirmed that the pressure-adjustment method is more effective and reasonable compared to its counterpart, the gas pre-charge method (Cheng, et al., 2012). For this reason, only the experimental data from such approach will be used for analyses in this work. In addition, it has been also noticed that the largely-increased gas flow rate in the current system would lead to extremely dense distribution of bubbles within the water pool, as a result making bed apex even invisible. Therefore, an intermittent gas delivery method is employed for measuring. Its reasonability has been also verified in our previous publications (Cheng, et al., 2012).

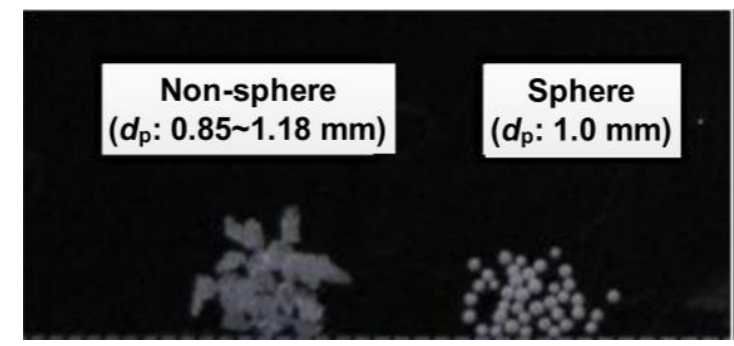

Fig. 5 A photograph of two alumina particles of different shapes.

During experiments, two video cameras, both capable of recording tens of frames per second, were used to record the movements of the particle bed through different directions. By using image analysis software, still frames extracted afterwards from the video recordings were used for quantitative measurement and analyses. Figure 6 demonstrates the definition of measured inclination angle of the mound used for the following analyses. Clearly, the inclination angle describes the overall average shape of the particle bed rather than its local periphery shape. To quantify the transient behavior associated with the leveling, we further introduce $R(t)$ :

$$
R(t)=\frac{\text { Bed angle at time } t}{\text { Initial bed angle } A_{0}(t=0 \mathrm{~s})}
$$

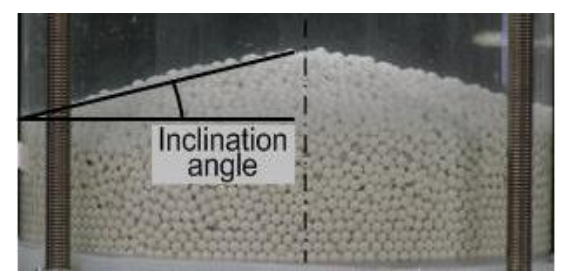

Fig. 6 Diagram of measured inclination angle.

To obtain the general characteristics of self-leveling with various kinds of particles, different gas flow rates were used. Table 2 lists the experimental parameter settings currently employed, including water depth ( $H_{\mathrm{w}}$ ), bed volume $\left(V_{\mathrm{pb}}\right)$, particle diameter $\left(d_{\mathrm{p}}\right)$, particle density (material), particle shape as well as gas flow rate $\left(Q_{\mathrm{g}}\right)$.

\section{Experimental analyses 3.1 Effect of gas flow rate}

Figure 7 summarizes the transient leveling behavior for several typical runs. Overall, it seems that with the exception of the cases using $6 \mathrm{~mm}$ alumina particles, higher gas flow rate seems to facilitate the leveling. In our previous studies performed at lower range of gas velocities (Cheng, et al., 2010b, 2011b; Zhang, et al., 2010, 2011), a similar influence of gas flow rate or its analogous role, the equivalent power density in bottom-heated and depressurized boiling experiments, was also recognized. This might be explained by the facts that as already verified in the microscopic flow regime studies (Cheng, et al., 2010a, 2011a, 2013a), gas velocity does have influence on the regime transition, i.e. as gas velocity increases, a greater impetus for lifting solid particles is attainable, thereby leading 
to the transition of bubbling behaviors, even from the trapping regime to the coalescing regime.

Table 2 Experimental parameters.

\begin{tabular}{|c|c|c|c|c|c|}
\hline Material & $d_{\mathrm{p}}[\mathrm{mm}]$ & $H_{\mathrm{w}}[\mathrm{mm}]$ & $V_{\mathrm{pb}}[\mathrm{L}]$ & $\begin{array}{c}\text { Initial angle } \\
\text { [degree] }\end{array}$ & $Q_{\mathrm{g}} \quad[\mathrm{L} / \mathrm{min}]$ \\
\hline \multirow{4}{*}{$\begin{array}{l}\text { Alumina } \\
\text { (sphere) }\end{array}$} & 1.0 & \multirow{9}{*}{180,400} & \multirow{4}{*}{7} & $19.1 \sim 20.0$ & $\sim 20.2$ \\
\hline & 2.0 & & & $17.7 \sim 19.5$ & $9.2 \sim 48.9$ \\
\hline & 4.0 & & & $17.4 \sim 18.9$ & $9.2 \sim 110.4$ \\
\hline & 6.0 & & & $17.5 \sim 19.0$ & $50.1 \sim 310.3$ \\
\hline $\begin{array}{c}\text { Alumina } \\
\text { (non-sphere) }\end{array}$ & $0.85 \sim 1.18$ & & 7 & $21.7 \sim 24.3$ & $\sim 51.7$ \\
\hline \multirow{3}{*}{$\begin{array}{l}\text { Zirconia } \\
\text { (sphere) }\end{array}$} & 2.0 & & $3,5,7$ & $17.5 \sim 20.4$ & $37.3 \sim 201.8$ \\
\hline & 4.0 & & \multirow{4}{*}{7} & $17.1 \sim 19.5$ & $98.1 \sim 205.8$ \\
\hline & 6.0 & & & $17.0 \sim 18.4$ & $103.6 \sim 310.3$ \\
\hline $\begin{array}{c}\text { Stainless } \\
\text { steel(sphere) }\end{array}$ & 2.0 & & & $17.7 \sim 18.4$ & $51.7 \sim 100.8$ \\
\hline $\begin{array}{l}\text { Stainless steel } \\
\text { (non-sphere) }\end{array}$ & $2.0 \sim 2.4$ & 180 & & $18.4 \sim 26.3$ & 52.3 296.7 \\
\hline
\end{tabular}

The reason why with increase of gas flow rate the difference is not so remarkable for the cases using 6 mm alumina beads within current conditions might be due to the relatively violent convection observed in the water pool. Currently, it is observable that for beds composed of smaller-sized beads (e.g. $2 \mathrm{~mm}$ )(Fig. 8(a)), which seems less of an obstruction to bubble movements, bubbles are observed to be much easier and more uniformly to pass through, while for beds packed with larger-sized particles (e.g. $6 \mathrm{~mm}$ ) (see Fig. 8(b)), due to the comparatively greater inertial resistance of a single particle as well as larger pores formed between particles, bubbles are quite susceptible to being obstructed, forced to weave around the gaps and finally detach the beds nonuniformly (Cheng, et al., 2012). The uneven distribution of detaching bubbling bundles tends to stir up the water pool and quite likely to cause convections. Overall, the convective flow seems to approximately counteract the driving impact of $Q_{\mathrm{g}}$ (Cheng, et al., 2012). To confirm our judgment, the horizontal deviation, defined as the ratio of distance between bed apex and the centerline of the test tank to the radius of the test tank, was measured. As shown in Fig. 7 (b), it is evident that for the cases using 6 $\mathrm{mm}$ alumina particles due to the pool convection, higher gas flow rate leads to comparatively larger deviation of bed apex. However, it should be noticed that for the $6 \mathrm{~mm}$ zirconia particles (see Fig. 7(c)), a purer influence of gas flow rate is observable, indicating that a less prominent influence of pool convection exists in those cases, which might be a consequence of relatively larger inertial resistance exerted due to a larger density (Cheng, et al., 2012).

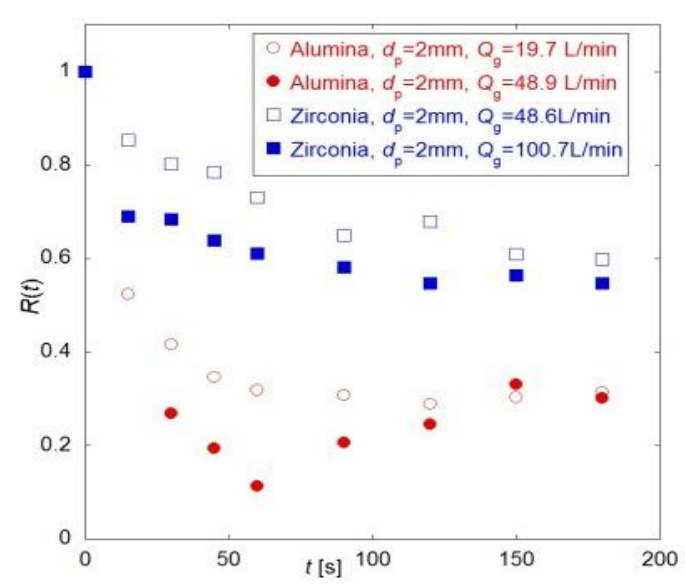

(a)

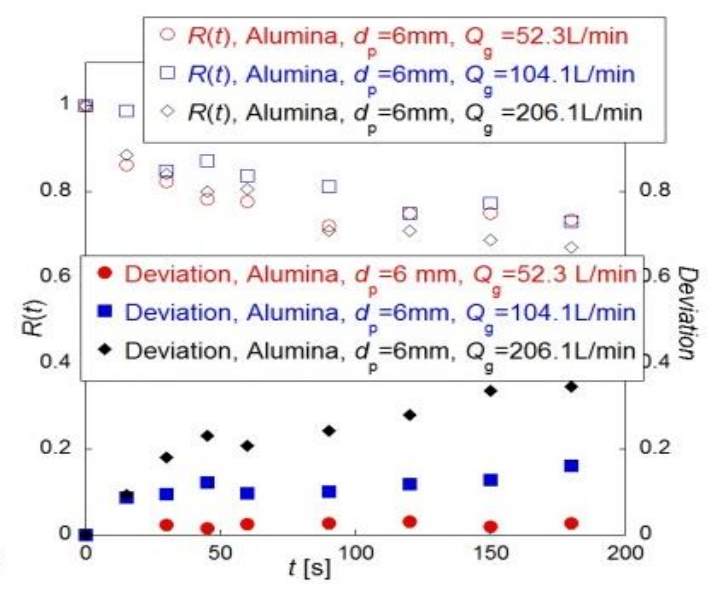

(b) 


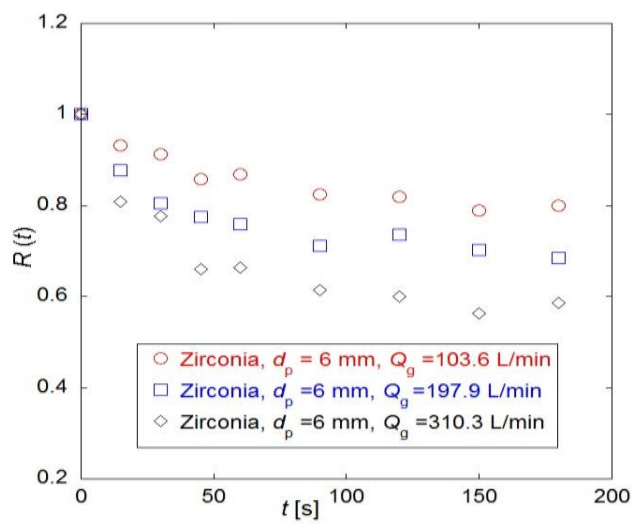

(c)

Fig. 7 Effect of gas flow rate $\left(H_{\mathrm{w}}=400 \mathrm{~mm}\right)$.

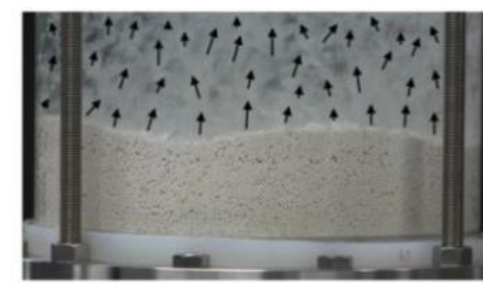

(a) $d_{\mathrm{p}}=2 \mathrm{~mm}, Q_{\mathrm{g}}=48.9 \mathrm{~L} / \mathrm{min}$

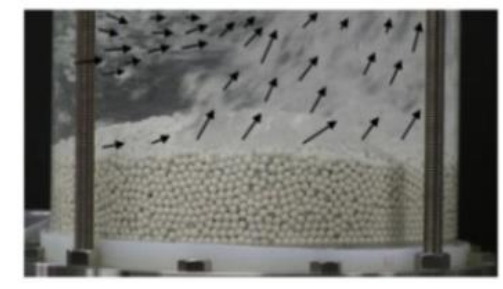

(b) $d_{\mathrm{p}}=6 \mathrm{~mm}, Q_{\mathrm{g}}=52.3 \mathrm{~L} / \mathrm{min}$

Fig. 8 Representative instants of leveling behavior for different particles (Alumina particles, $H_{\mathrm{w}}=400 \mathrm{~mm}$ ). (The arrows in the figure show the local flow directions.)

\subsection{Effect of water depth and bed volume}

In the previous studies using boiling method (Zhang, et al., 2010, 2011), it was recognized that water head has no remarkable impact on the self-leveling (see Fig. 9(a)), which perhaps indicates that the static pressure of liquid phase should not be so dominant in our investigations. However, under present setup, especially for the runs in which the impact of pool convection is much noticeable, an apparent difference is observable (see Fig. 9 (b)). This should be due to the fact that different water depth might lead to the changes in pool convection.

Figure 10 shows the effect of bed volume on the leveling behavior. Again, different from previous experiments performed at lower gas-velocities (Cheng, et al., 2010b, 2011b; Zhang, et al., 2010, 2011), an evident impact of bed volume on the leveling is observable, which might be also caused by pool convections which are changeable at varied bed-height.

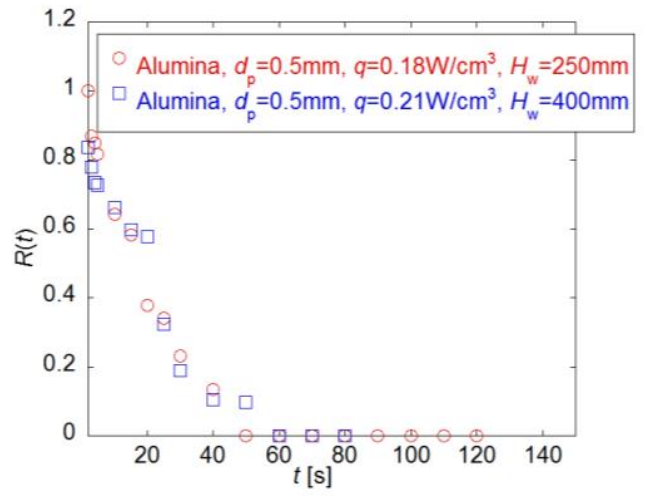

(a) Depressurization boiling

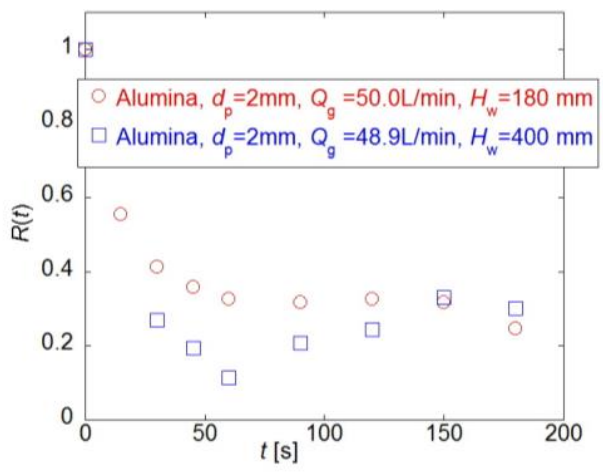

(b) Large-scale gas-injection

Fig. 9 Effect of water depth $\left(V_{\mathrm{pb}}=7 \mathrm{~L}\right)$. 


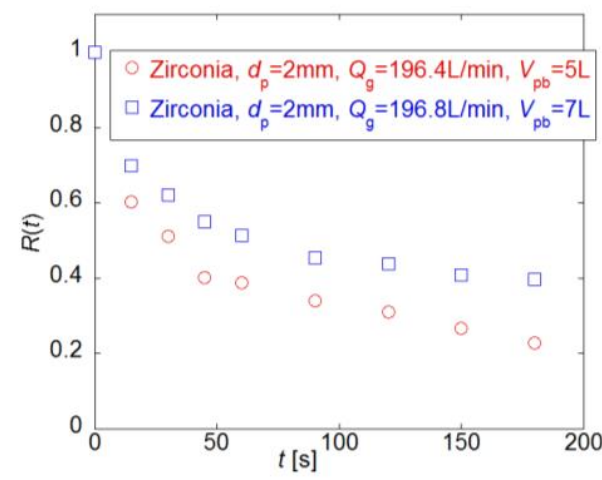

Fig. 10 Effect of bed volume ( $\left.H_{\mathrm{w}}=400 \mathrm{~mm}\right)$.

\subsection{Effect of particle properties (size, density and shape)}

Figures 11 and 12 respectively depict the transient variation of particle bed with particle size and density for several typical runs. Again, similar to former investigations at lower gas velocities (Cheng, et al., 2010b, 2011b; Zhang, et al., 2010, 2011), a slower decrease in $R(t)$ can be observed as particle diameter or density increases. This is because whatever the gas flow rate is, with the increase in particle size or density, particle becomes heavier and tends to be more difficult to be moved by the gas flow inside the bed, as confirmed in the flow-regime investigations (Cheng, et al., 2010a, 2011a).

Figure 13 illustrates the effect of particle shape on the self-leveling within current setup. It can be seen that similar to previous investigations at boiling conditions (Zhang, et al., 2011), the leveling behavior seems to proceed comparatively slowly for the runs using non-spherical particles. This might be explained by the additional collisions and frictions caused by some shape-related parameters, such as roughness or eccentricity.
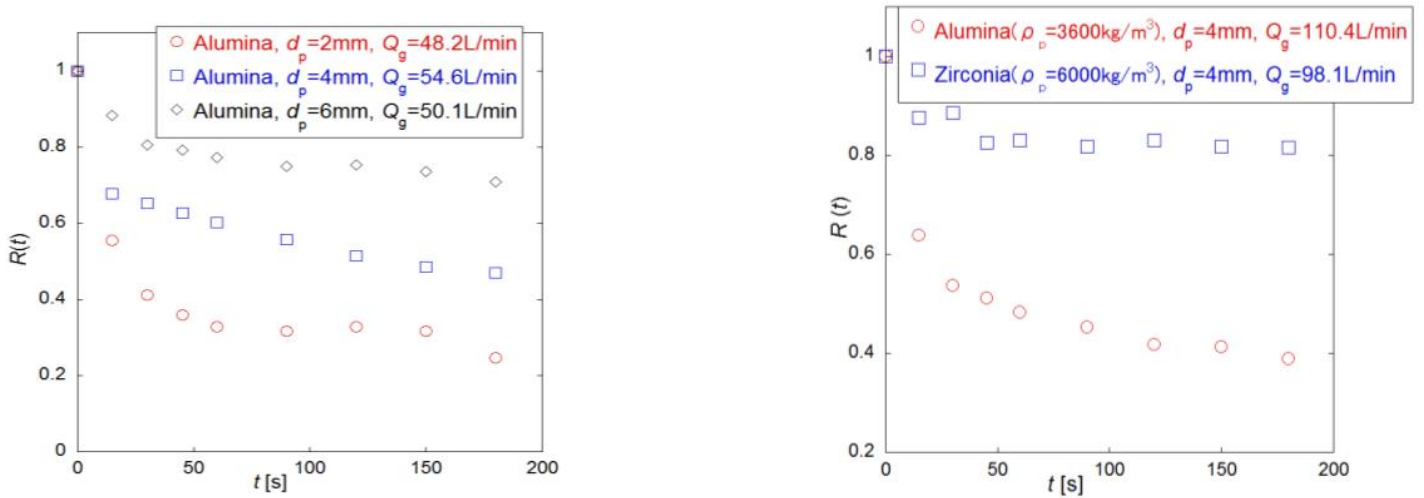

Fig. 11 Effect of particle size $\left(H_{\mathrm{w}}=180 \mathrm{~mm}\right)$. Fig. 12 Effect of particle density $\left(H_{\mathrm{w}}=180 \mathrm{~mm}\right)$.

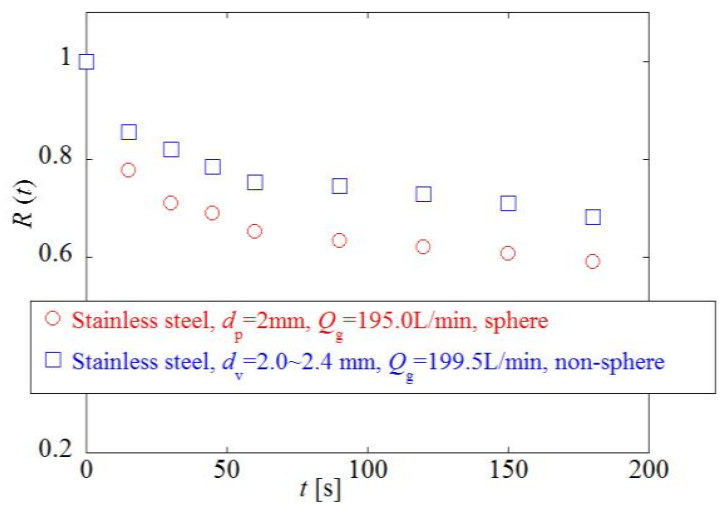

Fig. 13 Effect of particle shape $\left(H_{\mathrm{w}}=180 \mathrm{~mm}\right)$. 


\section{Status of developing empirical approach 4.1 Base model}

Although in the past, numerous experimental and model-based studies have been conducted in an attempt to clarify the fluidization behavior in multi-phase systems, their findings might not be directly applicable as for the self-leveling phenomenon the particle bed is far from fluidized (Cheng, et al., 2011b). However, we notice that when a particle is in a force balance state (gravity force, drag force and buoyancy force), particles in the medium have reached terminal velocity. Though self-leveling behavior is quite different from the force balance state, the terminal velocity of the particle or its transformative form might be effective in characterizing the leveling (Cheng, et al., 2011b, 2014; Zhang, et al., 2011). This thought is confirmable by several prior studies regarding the analysis of packed bed movement. For instance, Koide et al. $(1983,1984)$ and Abraham et al. (1992) experimentally studied the critical gas velocity ( $\left.U_{\text {gc }}\right)$ required for the suspension of solid particles (or particle aggregates) in three-phase columns. In their studies, column dimensions and shape, sparger design and properties of the liquid and solid particles were observed to have a strong influence on $U_{\mathrm{gc}}$. Using the transformative form of particle terminal velocity, they successfully proposed some rational empirical correlations to estimate $U_{\mathrm{gc}}$. Considering the obvious similarities between their investigations and the self-leveling behavior, as aforementioned, an empirical modeling method based on particle terminal velocity has been successfully developed over the quasi-2D small-scale setup (Cheng, et al., 2010b, 2011b). Recently, similar effort is also being attempted using the experimental data from current apparatus (Cheng, et al., 2013b). Motivated by a prior requirement of reliable experimental database and evidence for the verifications of the particle-based models that are being incorporated into the SIMMER-III code, here a data set with comparatively less prominence of pool convection ( $H_{\mathrm{w}}=180 \mathrm{~mm}, V_{\mathrm{pb}}=7 \mathrm{~L}$ ) is employed.

In an analogous manner, considering the characteristics of the leveling behavior observed (Cheng, et al., 2011b, 2014), the following dependency is assumed for the transient variation of $R(t)$ :

$$
\frac{1-R(t)}{1-R\left(t_{0}\right)}=\left(\frac{t}{t_{0}}\right)^{n}
$$

Where $n$ is a characteristic exponent defined to express the average leveling rate, and $R\left(t_{0}\right)$ is the ratio of inclination angle at a specific time $t_{0}$ to the initial angle $(0 \mathrm{~s})$. In addition, we believe that for the curre nt setup, the same group of dimensionless ratios $\left(\frac{U_{\mathrm{g}}}{V_{\mathrm{T}}}, \frac{\mu_{1} V_{\mathrm{T}}}{\sigma_{1}}, \frac{\rho_{\mathrm{p}}-\rho_{1}}{\rho_{1}}\right)$ utilized in previous modeling investigatio ns (Cheng, et al., 2010b, 2011b), should be also effective in reflecting the dependence of $R\left(t_{0}\right)$ and $n$ on th e experimental parameters of gas velocity, particle size and density. By making statistical analyses, the followi ng correlations were obtained with correlation coefficients of 0.979 and 0.954 , respectively.

$$
\begin{aligned}
& \log _{10} R\left(t_{0}=180 \mathrm{~s}\right)=0.671-0.100 \log _{10}\left(\frac{U_{\mathrm{g}}}{V_{\mathrm{T}}}\right)+0.635 \log _{10}\left(\frac{\mu_{1} V_{\mathrm{T}}}{\sigma_{\mathrm{l}}}\right)+0.465 \log _{10}\left(\frac{\rho_{\mathrm{p}}-\rho_{\mathrm{1}}}{\rho_{\mathrm{l}}}\right) \\
& \log _{10} n=0.55-0.105 \log _{10}\left(\frac{U_{\mathrm{g}}}{V_{\mathrm{T}}}\right)+0.745 \log _{10}\left(\frac{\mu_{1} V_{\mathrm{T}}}{\sigma_{\mathrm{l}}}\right)+0.445 \log _{10}\left(\frac{\rho_{\mathrm{p}}-\rho_{\mathrm{1}}}{\rho_{\mathrm{l}}}\right)
\end{aligned}
$$

where

$$
0.0034 \leq \frac{U_{\mathrm{g}}}{V_{\mathrm{T}}} \leq 0.067
$$

$0.369 \mathrm{~m} / \mathrm{s} \leq V_{\mathrm{T}} \leq 1.007 \mathrm{~m} / \mathrm{s}$

$2 \mathrm{~mm} \leq d_{\mathrm{p}} \leq 6 \mathrm{~mm}($ Spherical particles $)$ 
$2.6 \leq \frac{\rho_{\mathrm{p}}-\rho_{1}}{\rho_{1}} \leq 6.8$ (with water as liquid phase)

Combining Eqs. (2) (4), $\quad R(t)$ can be calculated. The comparison between experimental and predicted values of $R(t)$ is shown in Fig. 14. It seems that the above correlations describe relatively well all experimental points in current data set.

To further confirm the predictability of the developed equations, two additional runs that have not been used as a base for statistical analyses are employed for testing. As also shown in Fig. 14, current set of equations seems able to estimate those runs comparatively well (even for $d_{\mathrm{p}}=1 \mathrm{~mm}$ ), as a result promoting our confidence in its future applications.

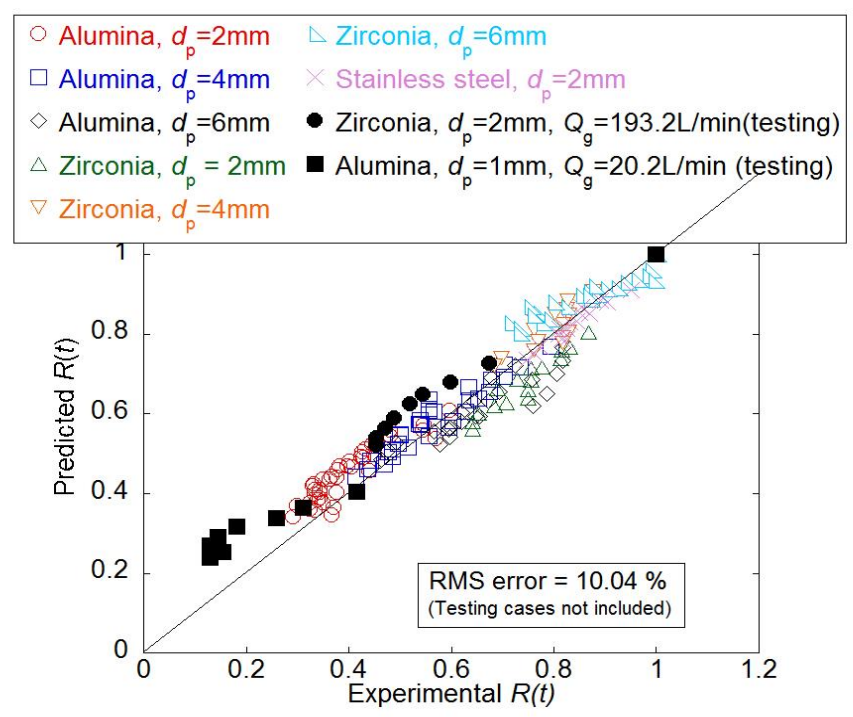

Fig. 14 Parity plot for $R(t)$.

Figures 15, 16 and 17 show the effect of particle size, particle density and gas flow rate on $R(t)$, respectively. From these figures, it is evident that the developed equations can represent those influences reasonably.

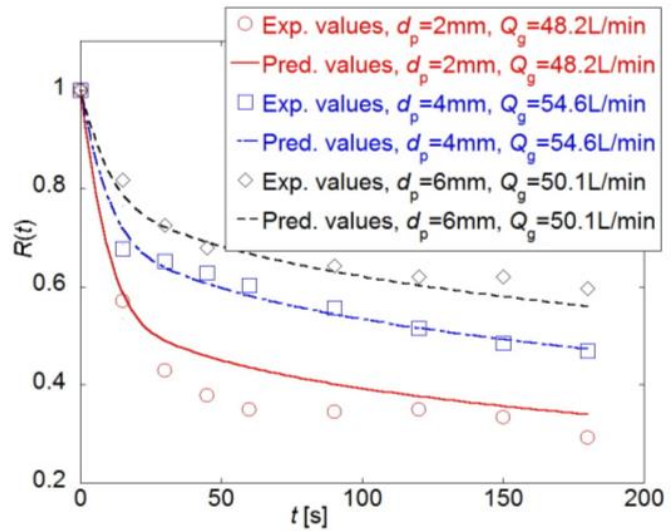

Fig. 15 Effect of particle size (Alumina, $Q_{\mathrm{g}}=50 \mathrm{~L} / \mathrm{min}$ ).

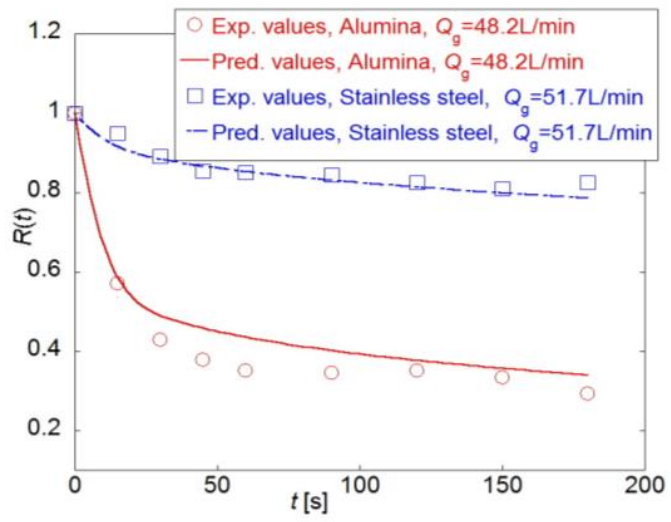

Fig. 16 Effect of particle density $\left(d_{\mathrm{p}}=2 \mathrm{~mm}, Q_{\mathrm{g}}=50 \mathrm{~L} / \mathrm{min}\right)$. 


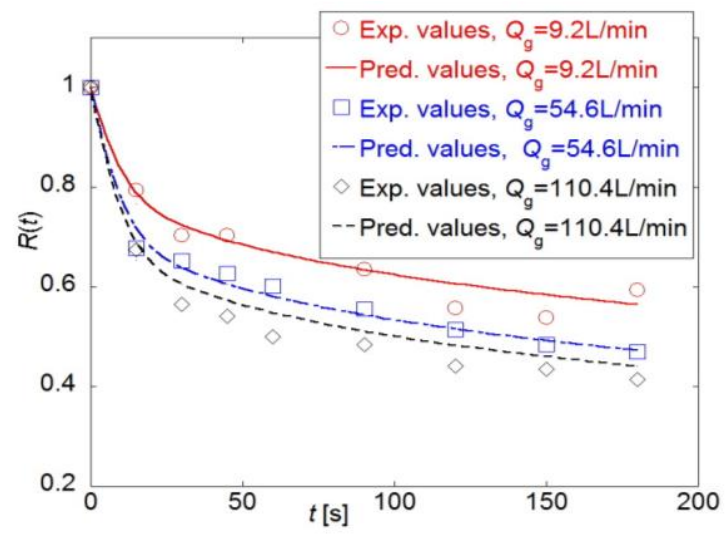

Fig. 17 Effect of gas flow rate (Alumina, $d_{\mathrm{p}}=4 \mathrm{~mm}$ ).

\subsection{Considerations of extension}

Although good agreement between experiments and the predictive results of the developed base model has been obtained as analyzed above, we should be aware that so far this model is restricted to calculations of homogeneous debris beds composed of spherical particles. However, in actual reactor accident conditions, debris mounds formed with multi-size multi-density non-spherical particles are more commonly encountered. For such complex situations, several extension schemes along with corresponding additional facilities are being considered and tested. In this section, the consideration of developing a potential scheme for covering the particle-shape influence is taken as an example for interpretation.

Since the particle terminal velocity is a critical parameter in the base model, it is natural that this term should be corrected as accurate as possible when we consider its extension. Fortunately, in the past decades, many empirical correlations relating the terminal velocity $V_{\mathrm{TN}}$ of non-spherical particles to some shape-related parameters were developed. For instance, Geldart (1990) suggested the following form for calculating $V_{\mathrm{TN}}$ :

$$
V_{\mathrm{TN}}=K_{\mathrm{T}} V_{\mathrm{TS}}
$$

Where $V_{\mathrm{TS}}$ is the terminal velocity of a sphere having the same volume $\left(d_{\mathrm{v}}\right)$, and $K_{\mathrm{T}}$ is a correction factor based on particle sphericity $\varphi$, which is generally defined as:

$$
\varphi=\frac{\text { surface area of a spherehaving the same volume as the particle }}{\text { external surface area of the particle }}
$$

By extending the work of Pettyjohn and Christiansen (1948), Geldart (1990) believed that $K_{\mathrm{T}}$ can be estimated from the following set of formulas:

$$
\begin{array}{ll}
\text { For } R e_{\mathrm{T}}<0.2, & K_{\mathrm{T}}=0.843 \times \log _{10}(\varphi / 0.065) \\
\text { For } R e_{\mathrm{T}}>1000, & K_{\mathrm{T}}=(0.43 /(5.31-4.88 \varphi))^{1 / 2}
\end{array}
$$

For $0.2<R e_{\mathrm{T}}<1000$,

$$
K_{\mathrm{T}}=\left[0.843 \times \log _{10}(\varphi / 0.065)-(0.43 /(5.31-4.88 \varphi))^{1 / 2}\right] \frac{1000-\operatorname{Re}_{\mathrm{T}}}{1000-0.2}+(0.43 /(5.31-4.88 \varphi))^{1 / 2}
$$

Where $R e_{\mathrm{T}}$ is the particle Reynolds number based on $d_{\mathrm{v}}$ at its terminal velocity.

On the other hand, as aforementioned, we notice that irrespective of "boiling" method, possibly due to additional particle-particle interaction caused by some shape-related parameters, particle shape is confirmable to have a suppressing role on the leveling (see Fig.13). To account for this influence, currently two correction functions $\left(K_{1}, K_{2}\right)$ are being considered for correcting the calculated values of $R\left(t_{0}\right)$ and $n$ (obtained from Eqs. (3) and (4)), respectively.

As can be seen clearly, the evaluation of $\varphi$ and determination of appropriate form for the correction functions $\left(K_{1}, K_{2}\right)$ play the dominant role in dictating the above-proposed extension scheme. Following the way of Geldart 
(1990), in our work a method by back-calculation of pressure drop through packed beds using the Ergun equation is recommended (Ergun, 1952):

$$
\frac{\Delta P}{H_{\mathrm{pb}}}=150 \frac{(1-\varepsilon)^{2}}{\varepsilon^{3}} \frac{\mu_{\mathrm{f}}}{\left(\varphi d_{\mathrm{v}}\right)^{2}} U_{\mathrm{f}}+1.75 \frac{(1-\varepsilon)}{\varepsilon^{3}} \frac{\rho_{\mathrm{f}}}{\varphi d_{\mathrm{v}}} U_{\mathrm{f}}^{2}
$$

Where $\Delta P / H_{\mathrm{pb}}$ is the pressure drop per unit bed height, $\varepsilon$ is bed voidage, $\mu_{\mathrm{f}}, \rho_{\mathrm{f}}$ and $U_{\mathrm{f}}$ are viscosity, density and superficial velocity of the working fluid, respectively. Appendix A gives a brief account for the pressure-drop measurement facility along with its justification using several spherical particles.

As for the additional correction functions $\left(K_{1}, K_{2}\right)$, currently some functional forms are being tested based on the parametric analyses of experimental data set. It has been recognized that in addition to particle properties (esp. the particle shape), the gas flow rate or its transformative form (e.g. the gas Reynolds number) might be also influential since a larger gas flow rate means a greater impetus for lifting solid particles, as confirmable in the flow-regime investigations (Cheng, et al., 2010a, 2011a, 2013a), as a result making the additional particle-particle resistance less prominent. Therefore, although at present stage, due to an insufficient database of non-spherical particles, it might be still beyond our ability to propose satisfactory functional forms for $K_{1}$ and $K_{2}$, the discussions here to some extent provide a guideline for our future studies under more realistic bed conditions (esp. for beds formed with non-spherical particles).

Finally, we have to stress that, as pointed out by many previous investigators (Geldart, 1990), although the numerical value of $\varphi$ does not describe the accurate shape of a particle, for most engineering purposes this limitation might not matter because it can represent the overall effect of shape on the hydrodynamic behavior which is of interest. On the other hand, we have also noticed the possibility that when the shape is totally different from a sphere (e.g. the sheet-like one), it might become not sufficiently accurate to employ the concept of sphericity to characterize the particle-shape influence. For this reason, currently some investigations with an aim to ascertain the most probable debris shapes that may be formed under CDA conditions have been considered. Although further confirmation would be necessary, we believe, by narrowing the range of shape distribution to some limited representative ones, the accuracy of sphericity should be theoretically maintainable. Further, as can be seen, the sphericity measured using Geldart's way, namely by back-calculation of the Ergun equation, is actually an effective one that incorporates somewhat overall bed effect. In other words, instead of the accurate shape (e.g. rugged periphery) of a single non-spherical particle, our attention is focused more on its overall (effective) hydraulic behavior. Lastly, one more point we need to restate is that, aside from further experimental investigations at various situations that might be encountered under reactor accident conditions, as mentioned-above, knowledge and database from experimental work will be also utilized for the improved verifications of some particle-based models that are being developed and incorporating into the SIMMER-III code (Cheng, et al., 2014). We believe, some of the potential issues (e.g. pool convection as well as the difference of thermo-physical properties between water and sodium) might be solvable as well by the well-verified SIMMER-III code in the near future.

\section{Concluding remarks}

To further confirm the mechanisms of debris bed self-leveling behavior, a series of experiments was performed by percolating nitrogen gas uniformly through particle beds at comparatively wide range of gas flow rates (up to around $300 \mathrm{~L} / \mathrm{min})$.

Through detailed analyses and comparisons, it was recognized that the findings regarding the influence of gas flow rate and particle properties that were obtained from previous investigations at lower range of gas velocities, can be generally extended to current conditions. However, aside from these factors, the pool convection was also confirmed to be crucial to the leveling behavior. Current parameters (such as particle size, gas flow rate, water depth and bed height) are observable to have influence on its formation and intensity.

Based on the quantitative data obtained, a set of empirical correlations (based model) was successfully developed. The predictability of those equations can be further confirmed by several testing runs that have not been used as a base for equation derivation. To predict the leveling behavior at more realistic bed conditions (e.g. beds formed with multi-size multi-density non-spherical particles), some extension schemes are being considered and tested. Although more investigations are still necessary, the preliminary discussions in this work provide a guideline for our future 
studies regarding the experimental analyses and empirical-model development.

\section{Acknowledgments}

The current work was supported by Japan Society for the Promotion of Science (JSPS) KAKENHI under Grant number 25420909. The experiments involved were mainly performed using the facilities in Kyushu University.

\section{Appendix A. Pressure-drop measurement experiment}

The experimental setup used to measure pressure drops is illustrated in Fig. A.1. A cylindrical column, with the effective dimensions of $54.5 \mathrm{~mm}$ in inner diameter and $200 \mathrm{~mm}$ in length, is utilized for holding particle beds. At the ends of both sides, two knit meshes of negligible resistance are installed to prevent the particles from leaving as well as for the uniform distribution of nitrogen gas which is used as working fluid. The bed pressure drop is measured by means of a precise differential pressure transducer. The gas flow rate, measured by a volumetric flow meter with accuracy up to $0.1 \mathrm{~L} / \mathrm{min}$, is adjusted over a comparatively wider range for experimental measurements. Temperatures and pressures at the inlet and outlet of the column are monitored as well.

Since the Ergun equation has proven itself reliable in predicting pressure gradients for packed beds with spheres over the past decades (Ergun, 1952), therefore, prior to any measurement for non-spherical particles, the developed facility and its measurement system are qualified by a series of validity tests using spheres. As shown in Fig. A.2, although some uncertainties are present possibly due to the potential parameters (e.g. particle roughness) that has not been considered in the Ergun equation, the comparatively good agreement to some extent justifies to the quality of our experimentation and instrumentation.

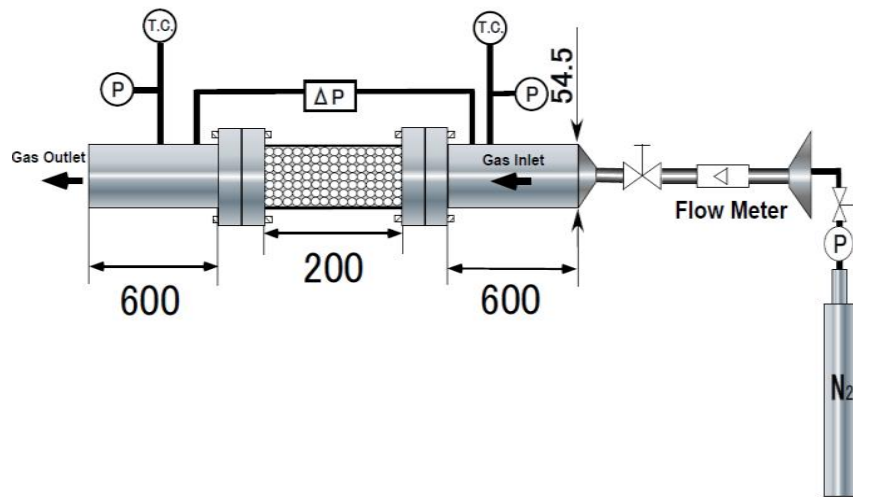

Fig. A.1 Schematic view of experimental setup for pressure-drop measurement.

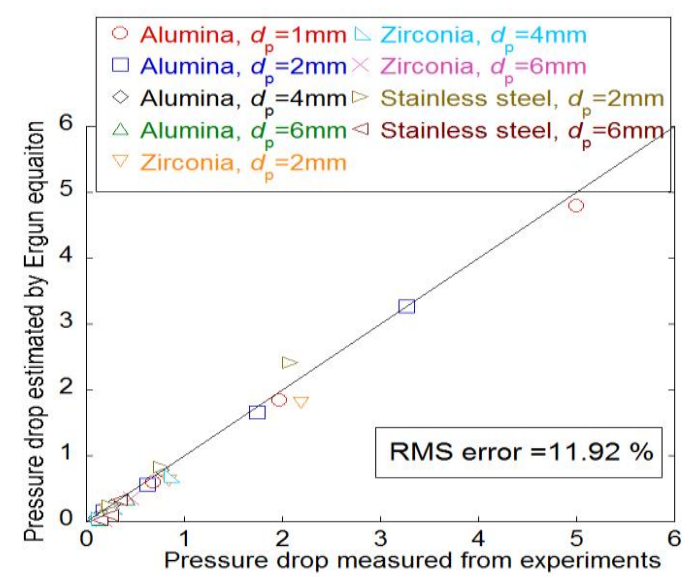

Fig. A.2 Comparisons between predicted and measured pressure drops using the test spheres.

\section{References}


Abraham, M., Khare, A. S., Sawant, S.B. and Joshi, J.B., Critical gas velocity for suspension of solid particles in three-phase bubble columns, Industrial \& Engineering Chemistry Research, Vol.31, No.4(1992), pp.1136-1147.

Alvarez, D. and Amblard, M., Fuel leveling, Proceedings of $5^{\text {th }}$ Information Exchange Mtg. on Post Accident Debris Cooling (1982), Karlsruhe, Germany, July 28-30, 1982.

Cheng, S., Hirahara, D., Tanaka, Y., Gondai, Y., Matsumoto, T., Morita, K., Fukuda, K., Yamano, H., Suzuki, T. and Tobita, Y., Experimental study of bubble behavior in a two-dimensional particle bed with high solid holdup, Proceedings of 18th International Conference on Nuclear Engineering (ICONE-18) (2010a), Xi'an, China, May $17-21,2010$.

Cheng, S., Tanaka, Y., Gondai, Y., Kai, T., Zhang, B., Matsumo, T., Morita, K., Fukuda, K., Yamano, H., Suzuki, T. and Tobita, Y., Experimental investigation on self-leveling behavior in debris bed, Proceedings of 7th Korea-Japan Symposium on Nuclear Thermal Hydraulics and Safety (NTHAS7) (2010b), Chuncheon, Korea, November 14-17, 2010.

Cheng, S., Hirahara, D., Tanaka, Y., Gondai, Y., Zhang, B., Matsumoto, T., Morita, K., Fukuda, K., Yamano, H., Suzuki, T. and Tobita, Y., Experimental investigation of bubbling in particle beds with high solid holdup, Experimental Thermal and Fluid Science, Vol. 35, No. 2(2011a), pp. 405-415.

Cheng, S., Tanaka, Y., Gondai, Y., Kai, T., Zhang, B., Matsumo, T., Morita, K., Fukuda, K., Yamano, H., Suzuki, T. and Tobita, Y., Experimental studies and empirical models for the transient self-leveling behavior in debris bed, Journal of Nuclear Science and Technology, Vol. 48, No. 10(2011b), pp. 1327-1336.

Cheng, S., Yamano, H., Suzuki, T., Tobita, Y., Gondai, Y., Nakamura, Y., Zhang, B., Matsumoto, T. and Morita, K., An experimental study on self-leveling behavior of debris beds with comparatively higher gas velocities, Proceedings of the Eighth Japan-Korea Symposium on Nuclear Thermal Hydraulics and Safety(NTHAS8) (2012), Beppu, Japan, December 9-12, 2012.

Cheng, S., Yamano, H., Suzuki, T., Tobita, Y., Nakamura, Y., Zhang, B., Matsumoto, T. and Morita, K., Characteristics of self-leveling behavior of debris beds in a series of experiments, Nuclear Engineering and Technology, Vol. 45, No. 3 (2013a), pp.323-334.

Cheng, S., Yamano, H., Suzuki, T., Tobita, Y., Nakamura, Y., Zhang, B., Matsumoto, T. and Morita, K., Empirical correlations for predicting the self-leveling behavior of debris bed, Nuclear Science and Techniques, Vol. 24, No. 1(2013b), pp.010602_1-010602_10.

Cheng, S., Tagami, H., Yamano, H., Suzuki, T., Tobita, Y., Zhang, B., Matsumoto, T. and Morita, K., Evaluation of debris bed self-leveling behavior: a simple empirical approach and its validations, Annals of Nuclear Energy, Vol. 63, No. 1(2014), pp.188-198.

Ergun, S., Fluid flow through packed columns, Chemical Engineering Progress, Vol. 48, No. 2(1952), pp.89-94.

Gabor, J.D., Simulation experiments for internal heat generation (1974), Reactor Development Program Progress Report ANL-RDP-32, Argonne National Laboratory, Argonne, USA.

Geldart, D., Estimation of basic particle properties for use in fluid-particle process calculations, Powder Technology, Vol. 60, No. 1(1990), pp.1-13

Guo, L., Morita, K. and Tobita, Y., Numerical simulation of three-phase flows with rich solid particles by coupling multi-fluid model with discrete element model, Proceedings of $20^{\text {th }}$ International Conference on Nuclear Engineering collocated with ASME 2012 Power Conference (ICONE20-POWER2012)(2012a), Anaheim, California, USA, July 30-Aug.3, 2012.

Guo, L., Morita, K. and Tobita, Y., Numerical simulation of bubbling fluidized beds by coupling multi-fluid Model with discrete element method, Proceedings of $8^{\text {th }}$ Japan-Korea Symposium on Nuclear Thermal Hydraulics and Safety (NTHAS8)(2012b), Beppu, Japan, December 9-12, 2012.

Hesson, J.C., Sevy, R.H. and Marciniak, T.J., Post-accident heat removal in LMFBRS: in-vessel considerations (1971), ANL-7859, Argonne National Laboratory, Argonne, USA.

Holdich, R.G., Fundamentals of particle technology (2002), Midland Information Technology \& Publishing, UK, pp.45-54.

Koide, K., Yasuda, T., Iwamoto, S., and Fukuda, E., Critical gas velocity required for complete suspension of solid particles in solid-suspended bubble columns, Journal of Chemical Engineering of Japan, Vol. 16, No.1(1983), pp. 7-12. 
Koide, K., Horibe, K., Kawabata, H., and Ito, S., Critical gas velocity required for complete suspension of solid particles in solid-suspended bubble column with draught tube, Journal of Chemical Engineering of Japan, Vol. 17, No.4(1984), pp.368-374.

Magallon, D., Hohmann, H., and Schins, H., Pouring of 100-kg-scale molten $\mathrm{UO}_{2}$ into sodium, Nuclear Technology, Vol. 98, No.1(1992), pp. 79-90.

Nakai, R., Suzuki, T., Yamano, H., Seino, H., Ishikawa, H., Kamiyama, K., Koyama, K. and Morita, K., Development of severe accident evaluation technology (level 2 PSA) for sodium-cooled fast reactors (1) overview of evaluation methodology development, Proceedings of 2009 International Congress on Advances in Nuclear Power Plants (ICAPP '09)(2009), Tokyo, Japan, May 10-14, 2009.

Nakai, R., Suzuki, T., Yamano, H., Seino, H., Ishikawa, H., Kamiyama, K., Koyama, K. and Morita, K., Development of level 2 PSA methodology for sodium-cooled fast reactors (1 overview of evaluation technology development, Proceedings of the 8th International Topical Meeting on Nuclear Thermal-Hydraulics, Operation and Safety (NUTHOS-8)(2010), Shanghai, China, October 10-14, 2010.

Pettyjohn, E.S. and Christiansen, E.R., Effect of particle shape on free-settling rates of isometric particles, Chemical Engineering Progress, Vol.44, No.2(1948), pp.157-172.

Tentner, A.M., Parma, E., Wei, T. and Wigeland, R., Evaluation of design measures for severe accident prevention and consequence mitigation (2010), ANL-GENIV-128, Argonne National Laboratory, Argonne, USA.

Tobita, Y., Kondo, S., Yamano, H., Morita, K., Maschek, W., Coste, P. and Cadiou, T., The development of SIMMER-III, an advanced computer program for LMFR safety analysis, and its application to sodium experiments, Nuclear Technology, Vol.153, No.3(2006), pp.243-263.

Waltar, A.E. and Reynolds, A.B., Fast breeder reactors (1981), Pergamon Press, New York, USA.

Zhang, B., Harada, T., Hirahara, D., Matsumoto, T., Morita, K., Fukuda, K., Yamano, H., Suzuki, T. and Tobita, Y., Self-leveling onset criteria in debris beds, Journal of Nuclear Science and Technology, Vol. 47, No.4 (2010), pp. 384-395.

Zhang, B., Harada, T., Hirahara, D., Matsumoto, T., Morita, K., Fukuda, K., Yamano, H., Suzuki, T. and Tobita, Y., Experimental investigation on self-leveling behavior in debris beds, Nuclear Engineering and Design, Vol. 241, No.1 (2011), pp. 366-377.

Zhang, B., Matsumoto, T., Morita, K., Yamano, H., Tagami, H., Suzuki, T. and Tobita, Y., Numerical simulation of the self-leveling phenomenon by modified SIMMER-III, Proceedings of $20^{\text {th }}$ International Conference on Nuclear Engineering collocated with ASME 2012 Power Conference (ICONE20-POWER2012) (2012), Anaheim, California, USA, July 30-August 3, 2012. 